\title{
Streamlined mail-based methods for large randomised trials: lessons learnt from the ASCEND study
}

\author{
Marion M. Mafham ${ }^{1}$ (I) $\cdot$ Louise J. Bowman ${ }^{1,2} \cdot$ Richard J. Haynes $^{1,2} \cdot$ Jane M. Armitage ${ }^{1,2}$
}

Received: 17 July 2019 / Accepted: 22 October 2019 / Published online: 30 November 2019

(C) The Author(s) 2019

\begin{abstract}
Reliable assessment of the effects of an intervention usually requires large randomised trials but such studies are becoming increasingly complex and costly to run. 'Streamlined' trials are needed in which every aspect of the trial design and conduct is simplified, retaining only those elements needed to answer the research question and ensure the safety of the individual participants. In this review we discuss how the trial 'A Study of Cardiovascular Events iN Diabetes' (ASCEND) was streamlined. The study included a two-by-two factorial design: it assessed the effects of low-dose aspirin and, separately, supplementation with $n$-3 fatty acids on serious vascular events in 15,480 people with diabetes but no overt cardiovascular disease. Other key streamlined design features, such as mail-based recruitment and follow-up, mainly by post, with no in-person visits and use of a run-in period, are also described. We go on to discuss the success of the study and other studies that have employed a similar mail-based approach, and the type of clinical trials that are suitable for mail-based design. Finally, we consider the limitations of the study, and how these could be circumvented in future studies. ASCEND randomised large numbers of eligible participants, achieved good adherence rates and almost complete follow-up at a fraction of the cost of traditional clinic-based trials. Such studies are necessary if researchers are to address the important clinical questions most relevant to improving health.
\end{abstract}

Keywords Aspirin $\cdot$ Cardiovascular $\cdot$ Fatty acid $\cdot$ Methodology $\cdot$ Randomised $\cdot$ Review $\cdot$ Streamlined

\author{
Abbreviations \\ ASCEND A Study of Cardiovascular Events iN Diabetes \\ EHR Electronic health record \\ GP General practitioner
}

\section{Introduction}

Reliable assessment of treatment effects requires randomised trials with unbiased assessment of large numbers of outcomes, complete follow-up of all randomised participants and

Marion M. Mafham

marion.mafham@ndph.ox.ac.uk

1 Clinical Trial Service Unit and Epidemiological Studies Unit, Nuffield Department of Population Health, University of Oxford, Richard Doll Building, Old Road Campus, Roosevelt Drive, Oxford OX3 7LF, UK

2 MRC Population Health Research Unit, Nuffield Department of Population Health, University of Oxford, Oxford, UK adequate adherence to the allocated treatment. However, randomised studies often include complex procedures that can hinder achievement of these aims. Large trials assessing serious clinical outcomes (Phase 3 or 4 studies) have become so costly that many important research questions go unanswered, while some potentially useful therapeutic agents are not brought to clinical testing $[1,2]$. Some investigators have suggested that observational analyses of large, complex, routinely collected datasets can be used to assess the effects of treatments without randomisation. However, such methods can lead to erroneous estimates of treatment effects since differences exist between those treated and not treated that are not captured within the dataset, and the bias resulting from these confounding factors can be as large, if not larger, than the treatment effect itself [3].

To obtain randomised trial evidence at feasible costs, 'streamlined' methods are needed. In such trials, every aspect of the study design and procedures is simplified as much as possible, retaining only the elements needed to answer the central research question and keep the individual participants safe [4]. Strategies to improve efficiency in trials include conduct in a small number of countries, simple eligibility 
criteria, limited data collection and the adoption of risk-based monitoring $[5,6]$. However, despite these measures, the cost of running large streamlined clinic-based outcome studies [7] remains high and such studies can often only be carried out in partnership with the pharmaceutical industry. 'Registry trials' in which participants are identified, randomised and followedup within an existing registry can be highly cost-effective [8, 9] and have been used in a number of settings, including percutaneous coronary procedures [10-12] and acute myocardial infarction [13]. However, such designs are not suitable or possible for many research questions, and other approaches to streamlining trials are needed.

'A Study of Cardiovascular Events iN Diabetes' (ASCEND) was designed to answer two important questions [14, 15]: for people with diabetes but no overt cardiovascular disease, is the risk of serious vascular events safely reduced by (1) low-dose aspirin or (2) supplementation with $n-3$ fatty acids? ASCEND used streamlined methods to achieve randomised trial evidence at as low a cost as possible. This review describes eight design features of the trial (Table 1) and considers how the lessons learnt can inform future studies.

\section{Streamlined design features of ASCEND}

Two-by-two factorial design By using a two-by-two factorial design, ASCEND was able to assess the effects of two independent treatments on serious vascular events within the same population $[14,15]$. Provided the effects of each treatment are moderate, such factorial designs have little impact on the statistical power of each analysis [16] and bring obvious efficiency savings by addressing two questions in one trial. It is frequently suggested that they are vulnerable to an interaction between the two treatments under study; however, if real, such interactions would be important to detect, and such a design is the most efficient way to do so. Despite the use of factorial designs in clinical trials for decades, this valuable method of increasing efficiency in randomised studies remains underused.

Mail-based trial design with no in-person visits ASCEND mainly used mail by post for recruitment, assessment of eligibility, consent, supply of study treatment and collection of follow-up information, i.e. there were no participant visits $[14,15]$. Other trials of aspirin, vitamins and fish oil supplementation have successfully used similar mail-based methods [17-21]; however, most recruited healthcare professionals (Table 2).

Mail-based trial designs result in a substantial cost saving over clinic-based methods but are not suitable for interventions where in-person procedures are necessary to assess eligibility, deliver the intervention, assess physical or biochemical outcomes or monitor individual participant safety (Table 3). However, careful planning can avoid some visits. For example, in ASCEND, baseline blood and urine samples were collected from two-thirds of the randomised cohort by mailing a sample collection kit and consent form and asking the participant to attend their local general practice for the blood to be taken. Samples were then mailed to the central laboratory [22, 23]. This also allowed baseline blood pressure, height and weight to be measured by the practice nurse. With advances in technology, an increasing number of assessments could be made using participants' smart phones or wearable devices, such as the assessment of cardiac rhythm [24]. Alternatively, if in-person baseline assessments are required, follow-up by postal mail or e-mail can still achieve substantial efficiency savings.

Study location ASCEND was conducted in a single country, which reduced cost and complexity. International collaboration is often necessary when recruiting individuals with a rare disease, but many trials in common diseases involve multiple countries. This is often driven by requirements of regulatory authorities to obtain trial data within particular countries, marketing strategies for new drugs and a perception that results from international trials are more generalisable than those from trials conducted in a single country. However, the proportional effects of treatment are not likely to vary by country unless there are substantial differences in disease pathophysiology or healthcare provision that modify the effects of the treatment. Obtaining the necessary regulatory and ethics committee approvals for international studies adds substantial complexity and delay [25], and operational procedures must be arranged for each country.

Furthermore, by recruiting participants entirely within the UK, low-cost long-term follow-up can be conducted via linkage to electronic health records (EHRs). This is particularly relevant for the aspirin vs placebo comparison, given the recently raised hypothesis that aspirin may reduce long-term cancer risk [26]. In ASCEND, pre-specified cancer analyses will be undertaken in 2022 and 2027 based on cancers identified from the UK Cancer Registry and from coded hospitalisation data.

Eligibility criteria Complex eligibility criteria, frequently requiring manual review of the participant's medical record and trial-specific blood or other tests, such as imaging, can have unhelpful consequences. The procedures required to implement such protocols can be time consuming and expensive and participants be may inappropriately excluded, limiting generalisability. To be eligible for ASCEND, potential participants had to fulfil just six criteria. They had to be at least 40 years of age at the time the screening questionnaire was sent, have a clinical diagnosis of diabetes mellitus, no clear indication for aspirin (e.g. diagnosed occlusive arterial 
Table 1 Key streamlined design features of the ASCEND trial

\begin{tabular}{|c|c|c|}
\hline Feature & Traditional design & ASCEND design \\
\hline Factorial design & Under-used & Two-by-two factorial design enabled two questions to be answered \\
\hline Recruitment and assessment & Clinic-based with multiple sites & No clinics. Mail-based recruitment and follow-up, mainly by post \\
\hline Study organisation & Multiple countries & Conducted within the UK \\
\hline Run-in period & Under-used in many trials & Two month placebo run-in managed by postal mail improved later adherence \\
\hline Eligibility criteria & $\begin{array}{l}\text { Complex criteria requiring blood or other } \\
\text { tests and review of medical notes }\end{array}$ & Simple criteria that can be determined from participant self-report \\
\hline Baseline assessments & $\begin{array}{l}\text { Complex assessments, including } \\
\text { collection of biological samples in } \\
\text { all participants }\end{array}$ & $\begin{array}{l}\text { Limited data collection } \\
\text { Optional blood and urine sampling }\end{array}$ \\
\hline Outcome adjudication & $\begin{array}{l}\text { Double adjudication by Clinical } \\
\text { Outcomes Committee }\end{array}$ & Single adjudication using pragmatic procedures \\
\hline Post-trial follow-up & $\begin{array}{l}\text { Seldom undertaken and rarely possible } \\
\text { in international trials }\end{array}$ & Low-cost post-trial follow-up through linkage with routine healthcare records \\
\hline
\end{tabular}

disease) and no clear contraindication to aspirin (e.g. recent gastrointestinal haemorrhage or peptic ulcer; use of anticoagulant; or history of aspirin allergy). Participants had to be free of severe comorbid disease that might limit their ability to remain in a long-term study, and both the participant and their doctor had to be uncertain about whether antiplatelet or $n$-3 fatty acid therapy conferred worthwhile benefit.

Run-in period Maintenance of adherence to the study intervention in randomised trials is critical to ensure adequate statistical power to detect plausible moderate effects. Although ethical standards require trial participants to be free to stop any aspect of participation at any time, every effort should be made to randomise only those participants who are likely to remain adherent for the duration of the study. A run-in period prior to randomisation during which treatment (active or placebo, depending on the circumstance) is taken provides a useful method of identifying participants prior to randomisation who are likely to be non-adherent so that they can be excluded. A run-in period may be particularly valuable in mail-based studies since research staff are unable to make a detailed face-to-face assessment of likely long-term adherence. In ASCEND, more than $40 \%$ of eligible individuals entering the placebo run-in period were not randomised, predominantly because they were unwilling to continue in the trial or failed to respond to questionnaires. If these individuals had been randomised immediately after assessment of eligibility, the resulting reduction in treatment adherence would have led to catastrophic loss of statistical power [23].

Limited baseline assessments In many trials, complex baseline assessments can include long questionnaires, clinical measurements, collection of biological samples and other tests. The rationale for these assessments includes confirmation of eligibility, characterisation of the cohort and to allow subgroup analyses. While some trials may require biochemical or physical measures to determine eligibility, or as part of the outcome assessments, a random sample of the population is often sufficient. In ASCEND, baseline data were limited to self-reported information about diabetes history, cardiovascular risk factors and non-study medication use. The non-mandatory blood and urine samples collected at the participants' local general practices, which were mailed to the central laboratory, enabled further characterisation of around two-thirds of the randomised cohort, which allowed assessment of the effects of the treatment in various subgroups defined by laboratory results (e.g. $\mathrm{HbA}_{1 \mathrm{c}}$ ). If this approach is used in a large randomised trial, the proportion of individuals without a valid sample at baseline should be equally distributed between the treatment groups, so that subgroup analyses can simply include a separate subgroup for those individuals without a valid result.

Outcomes adjudication In a typical clinic-based trial, adjudication of cardiovascular outcomes often does not alter the main findings but does consume substantial resource [27]. In ASCEND, the ability of participants to accurately report cardiovascular and bleeding events, the key primary, secondary and safety outcomes, was unknown and so such outcomes were adjudicated. Provided adjudication is undertaken blind to treatment allocation, misclassification of small numbers of events does not introduce bias and has little effect on statistical power [3]. Therefore, a streamlined approach was taken, with limited collection of supporting documents from the participants' general practitioners (GPs) and adjudication of each event by a single trained adjudicator blind to treatment allocation. Unrefuted participant-reported events (i.e. those for which the adjudication procedure was unable to confirm or refute the event because of lack of information) were included in the analysis. The validity of this approach for future studies depends on the outcomes considered. For some outcomes, such as hypoglycaemia, confirmation from GP records may not be useful and for outcomes that are not well reported by 
Table 2 Large randomised trials conducted by mail

\begin{tabular}{|c|c|c|c|c|c|c|}
\hline Study (year completed) & $\begin{array}{l}\text { BDS } \\
1988[18]\end{array}$ & $\begin{array}{l}\text { PHS } \\
1989 \text { [19] }\end{array}$ & $\begin{array}{l}\text { WHS } \\
2005 \text { [17] }\end{array}$ & $\begin{array}{l}\text { WACS } \\
2007[20]\end{array}$ & $\begin{array}{l}\text { ASCEND } \\
2017[14,15]\end{array}$ & $\begin{array}{l}\text { VITAL } \\
2018[21]\end{array}$ \\
\hline Intervention & Aspirin & Aspirin, $\beta$ carotene & Aspirin, vitamin E & $\begin{array}{l}\text { Vitamin } C \text {, vitamin } \\
\text { E, } \beta \text { carotene }\end{array}$ & Aspirin, $n-3$ FA & $\begin{array}{l}\text { Vitamin D } \\
n-3 \text { FA }\end{array}$ \\
\hline Population & UK doctors & US doctors & $\begin{array}{l}\text { Female health } \\
\text { professionals }\end{array}$ & $\begin{array}{l}\text { Women with, or at } \\
\text { high risk of CVD }\end{array}$ & Diabetes & General population \\
\hline Invitations & $\sim 20 \mathrm{~K}$ & $0.26 \mathrm{M}$ & $1.7 \mathrm{M}$ & $53 \mathrm{~K}^{\mathrm{a}}$ & $0.4 \mathrm{M}$ & $\sim 9 \mathrm{M}$ \\
\hline Randomised & 5139 & 22,071 & 39,876 & 8171 & 15,480 & 25,871 \\
\hline $\begin{array}{l}\text { Mean or median } \\
\text { follow-up (years) }\end{array}$ & $\sim 5$ & 4.8 & 10.1 & 9.4 & 7.4 & 5.3 \\
\hline
\end{tabular}

${ }^{a}$ Invited female health professionals who had already expressed interest in research

BDS, British Doctors Study; CVD, cardiovascular disease; FA, fatty acid; PHS, Physicians Health Study; VITAL, VITamin D and OmegA-3 TriaL; WACS, Women's Antioxidant Cardiovascular Study; WHS, Women's Health Study

participants, inclusion of unrefuted cases might not be appropriate. Analyses assessing the impact of adjudication on the main ASCEND trial results will be detailed in a later publication.

\section{Lessons learnt from the practical implementation of the ASCEND study design}

The lessons learnt from implementing the streamlined design features of ASCEND are summarised in Table 4.

\section{Participant identification and invitation The ASCEND} recruitment procedures are described in detail elsewhere [22]. Potentially eligible patients with diabetes were identified from electronic searches of centrally held diabetes registers (e.g. for retinopathy screening) in collaboration with local investigators, for which permission was obtained under UK national privacy legislation (Section 251 of the Health and Social Care Act). This allowed details of identified patients to be transferred securely to the coordinating centre in order to generate invitations on behalf of the collaborating investigator. Participants were also identified from GP-held registries, facilitated by local research networks. Practices searched their electronic records for eligible individuals with diabetes and mailed them an invitation pack (including an invitation letter, screening questionnaire including the consent form, information leaflet and freepost envelope) that had been provided preassembled by the coordinating centre. Obtaining a sufficient number of potentially eligible patients for invitation required collation of 58 separate diabetic register datasets and liaison with 785 general practices.

Assessment of eligibility, consent and pre-randomisation runin period Around 400,000 people were mailed an invitation pack by post and around one third returned a valid screening form. Screening forms were logged, checked and scanned using optical character recognition software. Eligibility for the study was determined from the participant's responses on the screening questionnaire. The questionnaire contained binary questions [e.g. 'Has a doctor ever told you that you had a stroke or ministroke (sometimes called TIA)?'] along with some questions requesting a written description from the participant. These written responses were reviewed by a

Table 3 Characteristics of clinical trials suitable for mail-based design

\begin{tabular}{|c|c|c|}
\hline & Mail-based design suitable & Mail-based design unsuitable \\
\hline Healthcare system & $\begin{array}{l}\text { National healthcare system with access to centralised } \\
\text { medical records available }\end{array}$ & $\begin{array}{l}\text { Local healthcare systems comprising multiple providers with no } \\
\text { centralised medical records }\end{array}$ \\
\hline Eligibility & $\begin{array}{l}\text { Eligibility can be identified from routine healthcare } \\
\text { records and/or patient report (e.g. prior stroke or } \\
\text { myocardial infarction) }\end{array}$ & $\begin{array}{l}\text { Eligibility requires detailed review of medical notes (e.g. heart } \\
\text { failure with reduced ejection fraction) or recent blood results } \\
\text { (e.g. kidney function) }\end{array}$ \\
\hline Intervention & $\begin{array}{l}\text { Suitable for administration in remote settings (e.g. } \\
\text { oral medication) }\end{array}$ & $\begin{array}{l}\text { Requires administration in a healthcare setting (e.g. devices) } \\
\text { or in-person participant education (e.g. injectable therapies) }\end{array}$ \\
\hline Safety monitoring & $\begin{array}{l}\text { No requirement for regular blood or other tests to } \\
\text { monitor safety }\end{array}$ & Requires regular blood or other tests to monitor safety \\
\hline Outcomes & $\begin{array}{l}\text { Can be identified from routine healthcare records } \\
\text { or self-report (e.g. cardiovascular events) }\end{array}$ & $\begin{array}{l}\text { Require in-person assessment (e.g. measurement of physical } \\
\text { function) }\end{array}$ \\
\hline
\end{tabular}


Table 4 Lessons learnt from the practical implementation of the ASCEND study design

\begin{tabular}{|c|c|c|c|}
\hline Study aspect & ASCEND process & Lessons learnt & Future possibilities \\
\hline $\begin{array}{l}\text { Identification of } \\
\text { potentially eligible } \\
\text { individuals }\end{array}$ & $\begin{array}{l}\text { Searches of healthcare data (e.g. } \\
\text { retinopathy registries) and GP lists }\end{array}$ & $\begin{array}{l}\text { Obtaining permissions and managing } \\
\text { formats for multiple datasets caused } \\
\text { delay }\end{array}$ & $\begin{array}{l}\text { Search of National datasets (e.g. } \\
\text { Hospital Episode Statistics in } \\
\text { England and Wales) } \\
\text { Linkage with additional datasets } \\
\text { to refine eligibility prior to } \\
\text { invitation }\end{array}$ \\
\hline $\begin{array}{l}\text { Invitation to take } \\
\text { part }\end{array}$ & $\begin{array}{l}\text { Large numbers of centrally mailed } \\
\text { invitation letters sent by post }\end{array}$ & Response rate low & $\begin{array}{l}\text { Requirement to identify large } \\
\text { numbers of potentially eligible } \\
\text { individuals }\end{array}$ \\
\hline $\begin{array}{l}\text { Assessment of } \\
\text { eligibility }\end{array}$ & $\begin{array}{l}\text { Participant self-report on mailed } \\
\text { screening questionnaire }\end{array}$ & $\begin{array}{l}\text { Substantial resource needed to process } \\
\text { and check completed questionnaires }\end{array}$ & Online or app-based questionnaires \\
\hline Consent & $\begin{array}{l}\text { Mailed consent form with telephone } \\
\text { support from study nurses and } \\
\text { doctors }\end{array}$ & $\begin{array}{l}\text { Changing regulatory framework may } \\
\text { require a 'prior interview' }\end{array}$ & $\begin{array}{l}\text { Online or app-based consent materials } \\
\text { with interactive questions supported } \\
\text { by Skype or telephone interview }\end{array}$ \\
\hline Biological samples & $\begin{array}{l}\text { Optional blood collection (at local } \\
\text { general practice, mailed to a } \\
\text { central laboratory) }\end{array}$ & $\begin{array}{l}\text { Postal delays meant delayed processing } \\
\text { of samples } \\
\text { Response rate } \sim 70 \%\end{array}$ & Linkage to routine healthcare lab results \\
\hline $\begin{array}{l}\text { Collection of } \\
\text { follow-up data }\end{array}$ & $\begin{array}{l}\text { Mailed or online 6-monthly follow-up } \\
\text { questionnaires } \\
\text { Systematic chasing of non-responders }\end{array}$ & $\begin{array}{l}\text { Substantial resource needed to process } \\
\text { and check questionnaires and clarify } \\
\text { inconsistencies/missing answers }\end{array}$ & $\begin{array}{l}\text { Online or app-based participant } \\
\text { questionnaires } \\
\text { Ascertainment of outcomes from } \\
\text { routine healthcare data }\end{array}$ \\
\hline $\begin{array}{l}\text { Maintaining } \\
\text { adherence }\end{array}$ & $\begin{array}{l}\text { Coordinating centre staff contacted } \\
\text { those wishing to stop treatment to } \\
\text { encourage continuing }\end{array}$ & $\begin{array}{l}\text { Required substantial resource at the } \\
\text { coordinating centre }\end{array}$ & $\begin{array}{l}\text { Direct discussion with participants } \\
\text { likely to still be required }\end{array}$ \\
\hline
\end{tabular}

clinician, with further details sought by telephone as needed. The screening and other ASCEND questionnaires are available online [23].

Consent required the person to confirm and sign that they had understood the implications of entering the trial having read the information leaflet and having had questions relating to trial entry, if any, addressed by telephone. Future trials will need to establish cost-effective methods of establishing valid consent without an in-person visit and regulations made sufficiently flexible to allow this. Such methods could include an online or app-based video describing the study, with a participantcompleted quiz to test understanding and support available by telephone, e-mail or skype to answer questions [28].

Consenting and eligible individuals entered a 2 month runin period and were sent a run-in pack of medication containing placebo aspirin and placebo $n$ - 3 fatty acids along with a medication information sheet and a copy of their signed consent form. An automated letter informed their GP of the patient's potential enrolment and asked them to contact the coordinating centre if they did not wish their patient to be randomised. Approximately 2 months after entering the runin period, participants were sent a randomisation questionnaire to confirm eligibility and willingness to continue.

The overall 'conversion rate' (i.e. the proportion of those invited who were randomised) was low. Around one-third of those invited returned a valid screening form but, of these, only about one fifth entered the run-in period $(6 \%$ of those invited) since the majority of respondents declined to take part. Approximately $40 \%$ of those entering the run-in period were not randomised [22, 23]. Overall, 4\% of those invited (15,480 participants) were randomised. Future studies using similar invitation methods need to ensure that large numbers of potentially eligible people are available to invite.

Few trials that use traditional clinic-based recruitment collect data on how many potential participants were approached for enrolment. The conversion rate from invitation to randomisation in ASCEND was similar to the other mailbased studies included in Table 2 and to a recently completed clinic-based cardiovascular trial which recruited 8000 participants in the UK by mailed invitation [29]. In ASCEND, available data for those who declined to take part was limited but those living in more deprived areas and older individuals were less likely to return a screening questionnaire indicating willingness to take part [22]. Future studies recruiting from within a single national dataset could undertake more detailed comparisons between those who did and did not take part. However, while differences in social deprivation, age, comorbidity or other factors between trial participants and the target patient population will affect the likely absolute harms or benefits, the proportional effects of treatment are likely to be generalisable.

Managing the mail-based recruitment process required considerable resources at the coordinating centre, including a $24 \mathrm{~h}$ freephone service for participants or their doctors. 
Bespoke computer programs were developed to enable and control all aspects of the trial. Dedicated trial managers, nurses and clinicians performed manual checks of the data and contacted the participants for clarification where necessary.

Recruitment to ASCEND took 6 years but could be faster in future. Identification of potentially eligible individuals from a single national dataset would bring substantial efficiency savings. Linkage with additional datasets, such as prescribing data, could refine eligibility prior to invitation and use of online or app-based forms to collect information about eligibility would eliminate many of the manual checks that were required to process the ASCEND screening forms.

Biological samples Approximately 2-4 weeks after entering the run-in period, participants were sent a blood and urine sample kit and asked to take it to their GP or other usual phlebotomy service. The kit included an information leaflet, a blood collection form (which included a section for recording of blood pressure, pulse, height and weight by the practice nurse) and a consent section (which included a request for consent for long-term storage of samples for future research). Samples were returned to the coordinating centre by mail. Previous stability studies have shown that a wide range of analytes (including $\mathrm{HbA}_{1 \mathrm{c}}$, lipids and cystatin $\mathrm{C}$ ) and genetic polymorphisms can be reliably measured in mailed samples at ambient temperature [30]. Sixty-three per cent of randomised participants returned a usable blood and/or urine sample within 4 days of sample collection and provided consent for analyses. Those who returned a sample were generally representative of the whole study population [23].

In future, linkage to routine laboratory data could increase efficiency and save money. In an ongoing registry trial in haemodialysis patients, local hospital blood results are obtained via the UK Renal Registry [31], while in a diabetes trial in Scotland (Clinical Trials.gov Identifier NCT03439345), linkage to the Scottish Care Information Diabetes Collaboration allows the study to collect routine blood and urine results.

Collection of follow-up information Every 6 months, participants were sent a short questionnaire asking about clinical events and admissions to hospital, adherence to the study treatments and use of anticoagulants or non-study antiplatelet agents. Each returned questionnaire was checked and scanned, with automated checks for missing or inconsistent responses. Any written descriptions of events or reasons for stopping the study treatment were reviewed by a study clinician and coded using bespoke software with clarification sought from the participant as necessary. Once coding was complete, details of any serious adverse events reported by participants were populated into the relevant tables within the database. Unless the participant or their doctor had requested that they stop their study treatment, further packs were mailed every 6 months. Serious adverse event reports could also be created by the coordinating centre clinicians if contacted directly by the participant or their doctor.

Throughout the study, the response to the 6-monthly participant follow-up questionnaire was generally over $90 \%$. However, achieving these response rates required considerable work. Participants were sent up to two reminder questionnaires, following which, if no response was received, staff at the coordinating centre made several attempts to contact the participant by phone before mailing a standard letter. If necessary, a call was made to an 'alternative contact' whose details were requested on the randomisation questionnaire. If participants still failed to respond, follow-up information was requested from their GP. In addition, the work involved in checking and processing paper follow-up forms was substantial. During the trial an online follow-up questionnaire was developed, which included in-built validation to reduce errors and inconsistencies. Participants who provided a valid e-mail address were given the option of receiving an e-mail link to a secure online version of the follow-up questionnaire. By the end of the study about a quarter of those who were still completing follow-up questionnaires were doing so online.

Future studies should aim to use participant-completed electronic data capture with either online or app-based questionnaires with or without additional use of linked EHR data for outcome ascertainment. In the ongoing Aspirin Dosing: A Patient-centric Trial Assessing Benefits and Long-term Effectiveness (ADAPTABLE) study, a streamlined webbased trial comparing two doses of aspirin in people with prior cardiovascular disease, vascular and bleeding events are assessed from participant reports supplemented by routine hospital claims data, with further investigation reserved for those events where a discrepancy exists [32]. However, future trials in countries with a single health provider or with good record linkage systems could potentially rely entirely on linkage to the EHRs, as is planned for an ongoing trial of allopurinol vs placebo in 5000 people with ischaemic heart disease in the UK [33]. Systems developed by regulatory agencies to link large numbers of health datasets for post-marketing surveillance, such as the EU-ADR web platform [34] and the FDA Sentinel Initiative [35], could be used to obtain outcomes for trials and embedded randomised trials are already part of the FDA Sentinel Initiative [35].

However, several hurdles remain before EHRs can replace clinical-based or questionnaire-based data collection for trials. First, careful validation must be undertaken for each outcome. Most cardiovascular outcomes assessed in ASCEND are accurately captured in the EHRs [36], but some outcomes (e.g. hypoglycaemia or transient ischaemic attack) may be difficult to assess from routinely collected data. For trials of investigational medicinal products, it may be necessary to receive data in a timely fashion to meet regulatory reporting requirements. Furthermore, open access to trial data may be limited by the data sharing agreements with the providers of 
linked healthcare data. In ASCEND, routinely collected data about cancer, cause of death and admissions to National Health Service (NHS) hospitals in the UK are available for almost all randomised participants and further publications will assess whether comparable results can be obtained using only EHR data.

Maintaining adherence with study treatment In ASCEND, any participant who expressed a wish to stop the study treatment or reported low adherence on their questionnaire was contacted by telephone to encourage continuation where appropriate. Participants who stopped the aspirin or placebo treatment were encouraged to continue with the $n-3$ fatty acids or placebo capsule and vice versa. Engagement was maintained with participants using regular newsletters and a study website. Using these procedures, weighted average adherence to study therapy while at risk of an event was $70 \%$ for the aspirin or placebo tablet and $76 \%$ for the $n-3$ fatty acids or placebo capsule over the mean follow-up duration of 7.4 years $[14,15]$, which is comparable to many clinic-based trials. Although future studies may make use of app-based or online communications and reminders to encourage adherence, it is likely that personal discussion with individuals to address their concerns will still be required to ensure good rates of adherence.

Verification of participant identity A key challenge for mailbased studies is the verification of the participant's identity and the authenticity of participant-completed responses. In ASCEND, potentially eligible participants were identified within routine healthcare records and therefore identifiers, such as date of birth, were known prior to invitation. For each questionnaire, participants were asked to record their date of birth as a verification check and visual inspection of the signature was undertaken by the coordinating centre staff. Future studies, particularly those in which data are collected online or via mobile device applications, must develop systems to verify the identity of respondents.

\section{Conclusions}

The key streamlined design features of ASCEND allowed a robust result to emerge at relatively low cost (estimated at less than $£ 10$ million [23]). However, future studies could recruit large numbers of participants and collect high-quality data more efficiently, for example, by using EHR data for both identification of participants and outcome ascertainment, and by collecting participant-reported data by online or app-based questionnaires. ASCEND has demonstrated that streamlined methods can obtain high-quality randomised trial evidence, sufficient to meet regulatory requirements and directly influence national and international guidelines [37]. Hopefully similar approaches will be adopted by other researchers, since trials need to become less complex and costly to run if important clinical questions most relevant to improving health are to be answered.

Acknowledgements We thank the participants, the collaborating doctors and general practitioners, Steering Committee and Data Monitoring Committee and all the administrative and clinical staff who have helped run the study.

Funding The ASCEND study is funded by grants to the University of Oxford from the British Heart Foundation (SP/03/002, SP/08/010/25939, $\mathrm{SP} / 14 / 3 / 31114, \mathrm{PG} / 05 / 013 / 18296$ ) and was supported by the NIHR Clinical Research Networks. The Clinical Trial Service Unit at the University of Oxford receives support from the UK Medical Research Council (which funds the MRC Population Health Research Unit in a strategic partnership with the University of Oxford), the British Heart Foundation, Cancer Research UK and the NIHR Oxford Biomedical Research Centre. We are grateful to Bayer Pharma AG who provided aspirin and placebo tablets and to Solvay, Abbott and Mylan who provided the $n-3$ FAs and placebo and for all companies for providing funding for drug packaging and to Bayer Healthcare LLC who contributed funding.

Duality of interest All authors work in the Clinical Trial Service Unit \& Epidemiological Studies Unit of the Nuffield Department of Population Health at the University of Oxford. The Clinical Trial Service Unit \& Epidemiological Studies Unit has a staff policy of not taking any personal payments directly or indirectly from industry (with reimbursement sought only for the costs of travel and accommodation to attend scientific meetings). It has received research grants from Abbott, AstraZeneca, Bayer, Boehringer Ingelheim, GlaxoSmithKline, The Medicines Company, Merck, Mylan, Novartis, Pfizer, Roche, Schering, and Solvay, which are governed by University of Oxford contracts that protect their independence.

Contribution statement All authors were responsible for drafting the article and revising it critically for important intellectual content. All authors approved the version to be published.

Open Access This article is distributed under the terms of the Creative Commons Attribution 4.0 International License (http:// creativecommons.org/licenses/by/4.0/), which permits unrestricted use, distribution, and reproduction in any medium, provided you give appropriate credit to the original author(s) and the source, provide a link to the Creative Commons license, and indicate if changes were made.

\section{References}

1. Eapen ZJ, Vavalle JP, Granger CB, Harrington RA, Peterson ED, Califf RM (2013) Rescuing clinical trials in the United States and beyond: a call for action. Am Heart J 165(6):837-847. https://doi. org/10.1016/j.ahj.2013.02.003

2. Moore TJ, Zhang H, Anderson G, Alexander GC (2018) Estimated costs of pivotal trials for novel therapeutic agents approved by the US Food and Drug Administration, 2015-2016. JAMA Intern Med 178(11):1451-1457. https://doi.org/10.1001/jamainternmed.2018. 3931

3. Collins R, Reith C, Emberson J et al (2016) Interpretation of the evidence for the efficacy and safety of statin therapy. Lancet 388(10059):2532-2561. https://doi.org/10.1016/S0140-6736(16) $31357-5$ 
4. Calvo G, McMurray JJ, Granger CB et al (2014) Large streamlined trials in cardiovascular disease. Eur Heart J 35(9):544-548. https:// doi.org/10.1093/eurheartj/eht535

5. Yusuf SR, Collins R, Peto R (1984) Why do we need some large, simple randomized trials? Stat Med 3(4):409-422. https://doi.org/ 10.1002/sim.4780030421

6. Eisenstein EL, Collins R, Cracknell BS et al (2008) Sensible approaches for reducing clinical trial costs. Clinical Trials 5(1): 75-84. https://doi.org/10.1177/1740774507087551

7. Green JB, Bethel MA, Armstrong PW et al (2015) Effect of sitagliptin on cardiovascular outcomes in type 2 diabetes. $\mathrm{N}$ Engl J Med 373:232-242

8. James S, Rao SV, Granger CB (2015) Registry-based randomized clinical trials - a new clinical trial paradigm. Nat Rev Cardiol 12(5): 312-316. https://doi.org/10.1038/nrcardio.2015.33

9. Zannad F, Pfeffer MA, Bhatt DL et al (2017) Streamlining cardiovascular clinical trials to improve efficiency and generalisability. Heart 103(15):1156-1162. https://doi.org/10.1136/heartjnl-2017311191

10. Rao SV, Hess CN, Barham B et al (2014) A registry-based randomized trial comparing radial and femoral approaches in women undergoing percutaneous coronary intervention: the SAFE-PCI for women (study of access site for enhancement of PCI for women) trial. JACC Cardiovasc Interv 7(8):857-867. https://doi.org/10. 1016/j.jcin.2014.04.007

11. Erlinge D, Omerovic E, Frobert $\mathrm{O}$ et al (2017) Bivalirudin versus heparin monotherapy in myocardial infarction. N Engl J Med 377(12):1132-1142. https://doi.org/10.1056/NEJMoa1706443

12. Lagerqvist B, Frobert O, Olivecrona GK et al (2014) Outcomes 1 year after thrombus aspiration for myocardial infarction. $\mathrm{N}$ Engl $\mathrm{J}$ Med 371(12):1111-1120. https://doi.org/10.1056/ NEJMoa1405707

13. Hofmann R, James SK, Jernberg T et al (2017) Oxygen therapy in suspected acute myocardial infarction. N Engl J Med 377(13): 1240-1249. https://doi.org/10.1056/NEJMoa1706222

14. ASCEND Collaborative Group (2018) Effects of aspirin for primary prevention in persons with diabetes mellitus. N Engl J Med 379(16):1529-1539

15. ASCEND Collaborative Group (2018) Effects of n-3 fatty acid supplements in diabetes mellitus. N Engl J Med 379(16):1540 1550

16. Peto R, Pike MC, Armitage P et al (1977) Design and analysis of randomized clinical trials requiring prolonged observation of each patient. II. Analysis and examples. Br J Cancer 35(1):1-39. https:// doi.org/10.1038/bjc.1977.1

17. Ridker PM, Cook NR, Lee IM et al (2005) A randomized trial of low-dose aspirin in the primary prevention of cardiovascular disease in women. N Engl J Med 352(13):1293-1304. https://doi. org/10.1056/NEJMoa050613

18. Peto R, Gray R, Collins R et al (1988) Randomised trial of prophylactic daily aspirin in British male doctors. Br Med J (Clin Res Ed) 296(6618):313-316. https://doi.org/10.1136/bmj.296.6618.313

19. Steering Committee of the Physicians' Health Study Research Group (1989) Final report on the aspirin component of the ongoing physicians' health study. N Engl J Med 321(3):129-135

20. Bassuk SS, Albert CM, Cook NR et al (2004) The women's antioxidant cardiovascular study: design and baseline characteristics of participants. J Women's Health 13(1):99-117. https://doi.org/10. 1089/154099904322836519

21. Manson JE, Cook NR, Lee IM et al (2019) Marine n-3 fatty acids and prevention of cardiovascular disease and cancer. N Engl J Med 380(1):23-32

22. Aung T, Haynes R, Barton J et al (2016) Cost-effective recruitment methods for a large randomised trial in people with diabetes: A
Study of Cardiovascular Events iN Diabetes (ASCEND). Trials 17(1):286. https://doi.org/10.1186/s13063-016-1354-9

23. Bowman L, Mafham M, Stevens W et al (2018) ASCEND: A Study of Cardiovascular Events iN Diabetes: characteristics of a randomized trial of aspirin and of omega-3 fatty acid supplementation in 15,480 people with diabetes. Am Heart J 198:135-144. https://doi. org/10.1016/j.ahj.2017.12.006

24. Turakhia MP, Desai M, Hedlin H et al (2019) Rationale and design of a large-scale, app-based study to identify cardiac arrhythmias using a smartwatch: the apple heart study. Am Heart J 207:66-75. https://doi.org/10.1016/j.ahj.2018.09.002

25. McNay LA, Tavel JA, Oseekey K et al (2002) Regulatory approvals in a large multinational clinical trial: the ESPRIT experience. Control Clin Trials 23(1):59-66. https://doi.org/10.1016/s01972456(01)00183-0

26. Rothwell PM, Price JF, Fowkes FG et al (2012) Short-term effects of daily aspirin on cancer incidence, mortality, and non-vascular death: analysis of the time course of risks and benefits in 51 randomised controlled trials. Lancet 379(9826):1602-1612. https://doi.org/10.1016/S0140-6736(11)61720-0

27. Ndounga Diakou LA, Trinquart L, Hróbjartsson A et al (2016) Comparison of central adjudication of outcomes and onsite outcome assessment on treatment effect estimates. Cochrane Database Syst Rev (3):MR000043. https://doi.org/10.1002/ 14651858.MR000043.pub2

28. Grady C (2017) Informed consent. New Engl J Med 376(9):856867. https://doi.org/10.1056/NEJMra1603773

29. The HPS3/TIMI55-REVEAL Collaborative Group (2017) Effects of anacetrapib in patients with atherosclerotic vascular disease. $\mathrm{N}$ Engl J Med 377:1217-1227

30. Clark S, Youngman LD, Palmer A et al (2003) Stability of plasma analytes after delayed separation of whole blood: implications for epidemiological studies. Int J Epidemiol 32(1):125-130. https://doi. org/10.1093/ije/dyg023

31. Bond S, Payne R, Wilson E et al (2015) Using the UK renal registry for a clinical trial in dialysis patients: the example of SIMPLIFIED. Trials 16(2):A15 (abstract)

32. Johnston A, Jones WS, Hernandez AF (2016) The ADAPTABLE trial and aspirin dosing in secondary prevention for patients with coronary artery disease. Curr Cardiol Rep 18(8):81. https://doi.org/ 10.1007/s11886-016-0749-2

33. Mackenzie IS, Ford I, Walker A et al (2016) ALL-HEART study group. Multicentre, prospective, randomised, open-label, blinded end point trial of the efficacy of allopurinol therapy in improving cardiovascular outcomes in patients with ischaemic heart disease: protocol of the ALL-HEART study. BMJ Open 6(9):e013774. https://doi.org/10.1136/bmjopen-2016-013774

34. Oliveira JL, Lopes P, Nunes T (2013) The EU-ADR Web Platform: delivering advanced pharmacovigilance tools. Pharmacoepidemiol Drug Saf 22(5):459-467. https://doi.org/10.1002/pds.3375

35. Platt R, Brown JS, Robb M et al (2018) The FDA sentinel initiative — an evolving national resource. N Engl J Med 379(22):20912093. https://doi.org/10.1056/NEJMp1809643

36. Wright FL, Green J, Canoy D et al (2012) Vascular disease in women: comparison of diagnoses in hospital episode statistics and general practice records in England. BMC Med Res Methodol 12: 161

37. Cosentino F, Grant PJ, Aboyans V et al (2019) ESC Guidelines on diabetes, pre-diabetes, and cardiovascular diseases developed in collaboration with the EASD. Eur Heart J pii:ehz486

Publisher's note Springer Nature remains neutral with regard to jurisdictional claims in published maps and institutional affiliations. 